\title{
dspace.vutbr.cz
}

\section{A Review of Thermal Conductivity of Epoxy Composites Filled with AIN or BN}

\author{
SAMEK, J.; ONDRŮŠEK, Č.; KURFÜRST, J.
}

Proceedings of the 2017 IEEE International Conference on Environment and Electrical Engineering and 2017 IEEE Industrial and Commercial Power Systems Europe (EEEIC / I\&CPS Europe)

elSBN: 978-1-5386-3917-7

DOI: http://dx.doi.org/10.1109/EEEIC.2017.7977576

Accepted manuscript

(C2017 IEEE. Personal use of this material is permitted. Permission from IEEE must be obtained for all other uses, in any current or future media, including reprinting/republishing this material for advertising or promotional purposes, creating new collective works, for resale or redistribution to servers or lists, or reuse of any copyrighted component of this work in other works. Josef Samek, Cestmir Ondrusek, Jiri Kurfurst, "A Review of Thermal Conductivity of Epoxy Composites Filled with AIN or BN", Proceedings of the 2017 IEEE International Conference on Environment and Electrical Engineering and 2017 IEEE Industrial and Commercial Power Systems Europe (EEEIC / I\&CPS Europe), pp. 1037-1042, 2018. DOI: 10.1109/EEEIC.2017.7977576. Final version is available at https://ieeexplore.ieee.org/document/7977576/ 


\section{A Review of Thermal Conductivity of Epoxy Composites Filled with AlN or BN}

\author{
Josef Samek, Cestmir Ondrusek \\ Department of Power Electrical and Electronic Engineering \\ Brno University of Technology \\ Brno, Czech Republic \\ josef.samek@vut.cz, ondrusek@feec.vutbr.cz
}

\author{
Jiri Kurfurst \\ Baumüller Brno, s.r.o. \\ Skalice nad Svitavou, Czech Republic \\ jiri.kurfurest@baumueller.de
}

\begin{abstract}
A new possibility to improve thermal properties and lifetime of electrical machines is adding some micro- or nano- particles to the epoxy resin and improve the heat dissipation of the machine. This will reduce the temperature in a stator winding. The paper reviews actual work in the field of epoxy materials enriched with aluminum nitride (AIN) or boron nitride (BN). Properties of the particles are described, same as preparation process and influence of usage of coupling agents that creates a bond between particles and epoxy. Brief introduction to the thermal aging of insulation is presented same as influence of the temperature reduction on lifetime of the winding insulation. Further suggestions for improvements and trends are established in discussion.
\end{abstract}

Keywords- Motors; stators; insulation; epoxy resins; nanocomposites; thermal conductivity; reliability;

\section{INTRODUCTION}

A composite material is made of two or more constituent materials with different physical or chemical properties. The materials mixed together create a new one material with significantly different properties.

The mixture of epoxy resin with some inorganic particles like aluminum dioxide, silicone dioxide, magnesium oxide, zinc oxide will create a particle reinforced composite. These composites have worse mechanical properties than fiber composites. But the inorganic particles have good thermal conductivity and also sufficient dielectric strength, so the resulting thermal conductivity of the composite will rise.

The aim of scientist in this field is to develop a composite with high thermal conductivity, low coefficient of thermal expansion, low dielectric constant, high electrical resistivity, high breakdown strength, high electrical treeing resistance and most importantly - low cost [1].

If we investigate an electric machine from the point of view of cooling, the worst thermally conductive part is the insulation system. According to [2], the thermal conductivity of pure epoxy resin moves between $0,15-0,3 \mathrm{~W} \cdot \mathrm{m}^{-1} \cdot \mathrm{K}^{-1}$. In this range moves also the thermal conductivity of copper enamel.

This research work has been carried out in the Centre for Research and Utilization of Renewable Energy (CVVOZE). Authors gratefully acknowledge the financial support from the Ministry of Education, Youth and Sports of the Czech Republic under NPU I programme (project No. LO1210).
The thermal conductivity of stator sheets moves between 25 and $35 \mathrm{~W} \cdot \mathrm{m}^{-1} \cdot \mathrm{K}^{-1}$ in plane of lamination according to provided information of different manufacturers and steel type. In normal to plane of lamination the thermal conductivity moves around $0,37 \mathrm{~W} \cdot \mathrm{m}^{-1} \cdot \mathrm{K}^{-1}$. The copper thermal conductivity moves around $380 \mathrm{~W} \cdot \mathrm{m}^{-1} \cdot \mathrm{K}^{-1}$.

Usage of impregnating epoxy resins with higher thermal conductivity is key point in improvement of the heat dissipation in electrical machines. Due to heat dissipation the efficiency of a machine can be improved.

In this review, there will be described preparation process and composites filled with $\mathrm{AlN}$ or $\mathrm{BN}$ particles will be compared.

\section{MICRO- AND NANO- PARTICLES}

There are many different chemical substances that can be mixed into the base epoxy matrix to improve the desired properties of the material and create a composite.

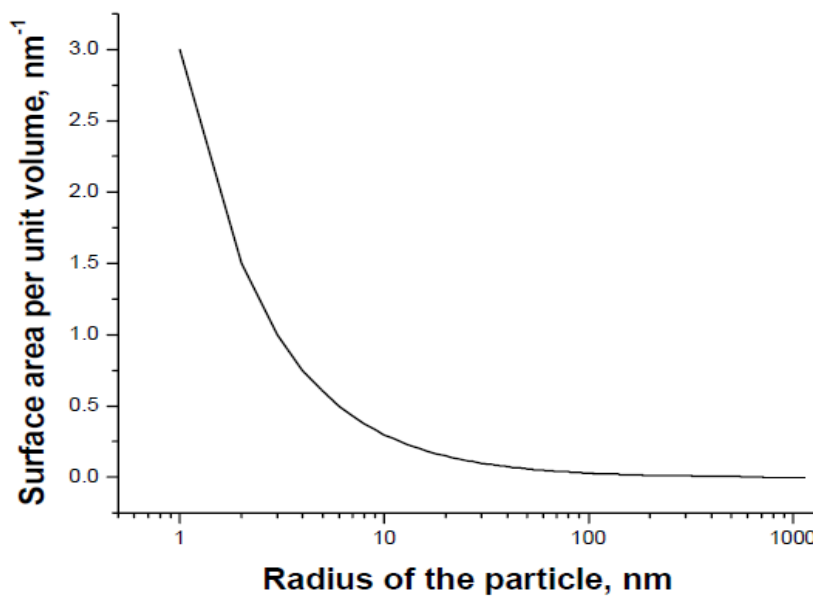

Fig. 1 - Surface to volume ratio of nanocomposites as a function of nanoparticle size [3]

According to the particle size we separate them to nanoand micro- particles. Micro particle's size is defined as $>1 \mu \mathrm{m}$ and nanoparticles are smaller. As we can see in Fig. 1, the greatest advantage of nanoparticles is their surface area. This offers us more place for coupling agent that improves bonding 
between particles and the base epoxy matrix. Coupling agent usually has also better thermal conductivity than pure epoxy.

Nitride particles provide perfect thermal conductivity compared with oxide particles - e.g. $\mathrm{SiO}_{2}$ or $\mathrm{Al}_{2} \mathrm{O}_{3}$. There should be mentioned, that the thermal conductivity of particles of the same material changes with crystalline form of the particles. Following TABLE 1 presents thermal conductivities of materials. Very good thermal conductivity has especially boron nitride $(\mathrm{BN})$ and aluminum nitride $(\mathrm{AlN})$.

TABLE 1 - Thermal conductivity of different materials at the room temperature, data were taken from [1], [2], [4]

\begin{tabular}{|c|c|}
\hline \multirow{2}{*}{ Material } & Thermal Conductivity \\
\cline { 2 - 2 } & $\mathrm{W} \cdot \mathrm{m}^{-1} \cdot \mathrm{K}^{-1}$ \\
\hline \hline Epoxy & $0,15-0,3$ \\
\hline Fused SiO2 & $1,5-1,6$ \\
\hline Crystalline silica & 3 \\
\hline Al2O3 & $25-42$ \\
\hline BN & $29-300$ \\
\hline AlN & $150-220$ \\
\hline ZnO & 60 \\
\hline
\end{tabular}

AlN is material that has very high thermal conductivity. In experiment [5] AIN provided even better properties of resulting composite over $\mathrm{BN}$. This happened due to amorphous boron nitride $(\mathrm{aBN})$, where AlN particles had different forms - hexagonal, spherical and cubic.

The only problem with usage of AlN particles is its oxidation resistance. We need stable particles for epoxy resins used for impregnation of windings. During aging of insulation, the oxidation of the nanoparticles could pose future problems. On the other hand in article [6] authors reached thermal conductivity $11 \mathrm{~W} \cdot \mathrm{m}^{-1} \cdot \mathrm{K}^{-1}$ with $60 \%$ volume fraction (vol.\%) filling in base epoxy matrix.

$\mathrm{BN}$ poses perfect thermal conductivity that moves between 29 and $300 \mathrm{~W} \cdot \mathrm{m}^{-1} \cdot \mathrm{K}^{-1}$ according to the crystalline form. The thermal conductivity of $\mathrm{BN}$ depends also on the purity of crystals. The best results along compared articles were achieved with the cubic boron nitride (c-BN) with $150 \mathrm{~nm}$ particle size [7] in field of nanocomposites. The thermal conductivity of $\mathrm{c}-\mathrm{BN}$ can reach up to $740 \mathrm{~W} \cdot \mathrm{m}^{-1} \cdot \mathrm{K}^{-1}$ in a pure crystal [8].

Hexagonal BN (h-BN) is also widely used for enrichment, but the particle shape of flakes or fin plates creates inhomogeneous thermal conductivity in direction of lamination $600 \mathrm{~W} \cdot \mathrm{m}^{-1} \cdot \mathrm{K}^{-1}$ and plane to lamination 30 $\mathrm{W} \cdot \mathrm{m}^{-1} \cdot \mathrm{K}^{-1}[9]$.

High thermal conductivity epoxies with h-BN and c-BN are presented in [10]. Surprisingly the h-BN composites posed better results in thermal conductivity over c-BN composites due to empty space (voids) in the resulting composite. A h-BN composite with $80 \%$ weight fraction (wt.\%) reached thermal conductivity of $10,1 \mathrm{~W} \cdot \mathrm{m}^{-1} \cdot \mathrm{K}^{-1}$ which corresponds to 55,3 vol. $\%$.

\section{COUPLING AgENT}

There are two basic types of composites. The first one is just a mixture of nanoparticles and epoxy resin. The second one uses a coupling agent that creates a chemical bond between nanoparticle and epoxy matrix.

The nanoparticles can be surface treated by manufacturer or without any treatment. Theoretical model - multi core model for coupling agent treated composites was presented in [11]. According to the model we can more easily understand reaction of the nanoparticles during physical measurements.

Effect of coupling agents was investigated in [12] where chemical substance silane posed best improvement in thermal conductivity compared with other coupling agents. In another study Silane Z-6020 [6] compared with Silane Z-6040 posed better results in covering of the surface of the nanoparticles. The proper amount of coupling agent is very important, as we can see in Fig. 2. Treatment of the AlN particles surface with Silane Z-6020 improved thermal conductivity of epoxy composite from 6,99 to $10,98 \mathrm{~W} \cdot \mathrm{m}^{-1} \cdot \mathrm{K}^{-1}[6]$.

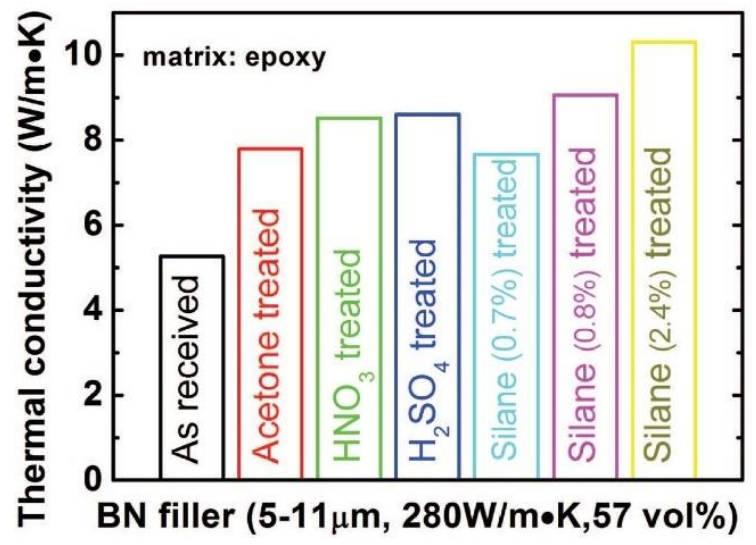

Fig. 2 - Influence of different coupling agents on thermal conductivity of final composite [1]

These days the silane coupling agent is commonly used for treatment of the surface of nanoparticles [5], [10], [13]-[19]. But the authors usually do not state the weight or volume fraction of used coupling agent. Usual amount of silane as a coupling agent in the composite moves around $1 \mathrm{wt} \%$.

\section{PREPARATION OF THE COMPOSITES}

Nanoparticles are usually delivered from a manufacturer in a form of powder. Manufacturers can treat surface of the particles or particles are treated in a laboratory during the composite preparation.

During preparation with "solvent technique" - Fig. 3, first of all the nanoparticles are dispersed in a solvent (usually. ethanol) and ultrasonicated at the room temperature. This prevents creation of agglomerations of the nanoparticles and leads to better dispersion of the particles. 


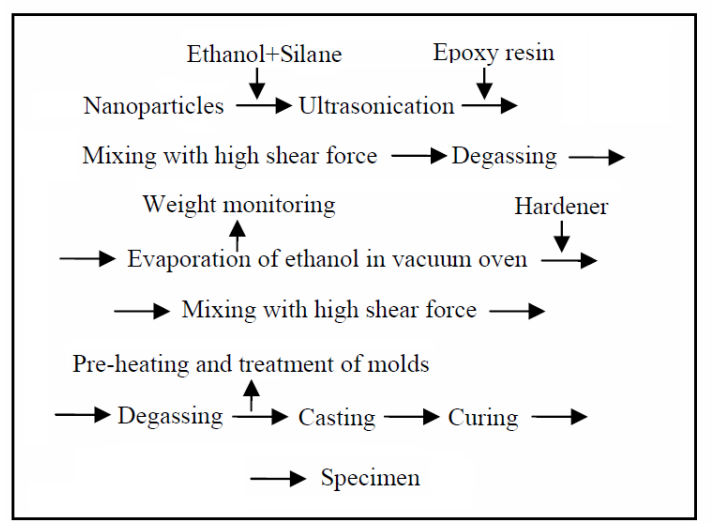

Fig. 3 - Schematics preparation of the composite specimen with solvent technique [13]

Time of ultrasonication differs in each article from 3 minutes [20] up to 1 hour [7], [19], [21]. For ultrasonication are used frequencies in range of $\mathrm{kHz}$ - e.g. $12 \mathrm{kHz}$ [22] or 42 $\mathrm{kHz}$ [23]. After ultrasonication the epoxy base resin is added. Afterwards the ethanol is evaporated at temperatures around $100{ }^{\circ} \mathrm{C}$ while the epoxy is stirred. Stirring is important for preservation of dispersion of the nanoparticles. Then the epoxy hardener is added to the solution. The material is degassed in vacuum. Afterwards the material is cast to a molds and cured at high temperatures $140{ }^{\circ} \mathrm{C}$ for 3 hours [24] or more and then the temperature is decreased to $100-130{ }^{\circ} \mathrm{C}$. Each authors use different curing process. This technique is commonly used in the scientific articles [5], [7], [10], [13], [13], [16], [17], [19].

Different preparation technique "speed mixer technique" pour out surface treated [24] or untreated [25] nanoparticles to the base epoxy. The particles are mixed with mixer or in better case with high speed centrifuge for good dispersion of nanoparticles for given time. Then the epoxy-hardener is added to the base epoxy. Finally, the curing process follows in the same order as written in the paragraph above. Other experiments with untreated surface of nanoparticles were presented in [3], [10], [13], [17] where authors reports better properties of composite with surface treated particles. Some authors used ball milling during this process [26], [27] and reported also better dispersion of particles.

Last technique "nanomizer" uses mechanical dispersion of nanofilling material agglomerations with special apparatus nanomizer (high pressure homogenizer) YSNM-1500, Yoshida Co. [6], [7]. The particles were mixed together with base epoxy and then pushed through $170 \mu \mathrm{m}$ small holes under pressure of $200 \mathrm{MPa}$ ten times. A schematic representation of nanomizer principle is presented in [7].

All three preparation techniques provide different quality of particle dispersion. The dispersion of particles was examined in [29], where usage of the nanomizer shows the best results. Speed mixer technique follows and the worst particle dispersion was achieved with solvent technique.

In [17] authors defined three basic types of composites according to the quality of the particle dispersion. The composite types are:
- Nanocomposites (NC) - the dispersion is good and the size of agglomerations (if they are observed) is not more than $100 \mathrm{~nm}$;

- Mesocomposites (MC) - the clusters of particles are larger than $100 \mathrm{~nm}$ but smaller than $500 \mathrm{~nm}$;

- Nano-meso-composites (NMC) - the dispersion of one type of particles is nanoscaled and another type has some agglomerates, which are larger than $100 \mathrm{~nm}$.

\section{THERMAL PROPERTIES OF THE COMPOSITES}

\section{A. Aluminum Nitride - AlN}

Many authors prepared composites with AlN or BN filling material. Now the preparation techniques and results will be compared.

Not many authors use pure AlN particles for preparation of epoxy specimens. Then there are authors that creates epoxies with high volume fraction of the filler [6], [10]. So only this [5], [13] studies left for comparison of results proper for impregnation of windings.

Both experiments [5], [13] used silane - exactly $\gamma$ glycidoxypropyltrimethoxysilane coupling agent for improvement of the adhesion between the filler particles and epoxy polymer. The particles were from one manufacturer with the particle size range between $20-500 \mathrm{~nm}$ with average particle size (APS) size $60 \mathrm{~nm}$ and $70 \%$ of them were smaller than $100 \mathrm{~nm}$. The particles had various shapes - hexagonal, cubic and spherical. The preparation technique of both sample lines was the "solvent technique". Results are presented in Fig. 4 and their comparison provides TABLE 2.

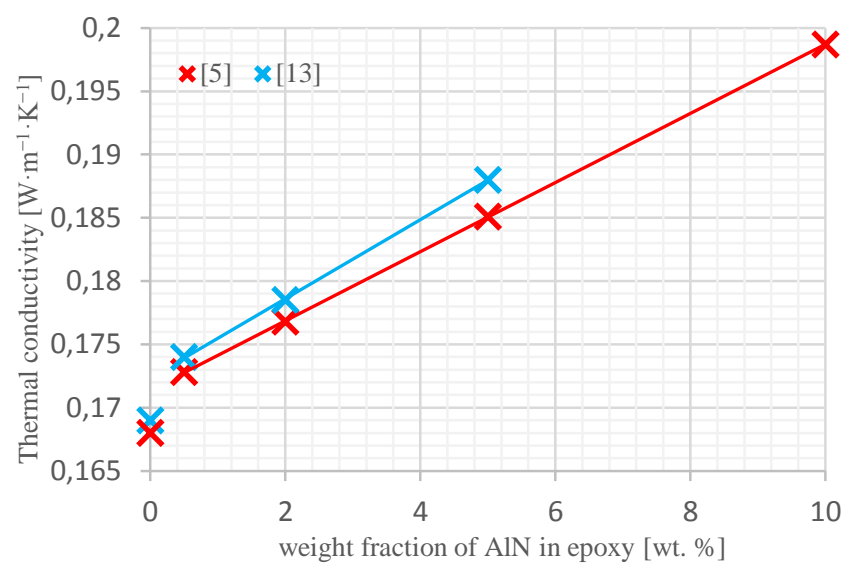

Fig. 4 - Epoxy composites with AIN nanoparticles, data were taken from [5], [13]

If we try to compare different experiments in TABLE 2 and TABLE 3 with base epoxy matrix of different thermal conductivity, we have to calculate relative percentage change.

$$
\text { p.c. }=\frac{\lambda_{w t . X \%}-\lambda_{w t .0 \%}}{\lambda_{w t .0 \%}} \cdot 100
$$

Where p.c. represents percentage change in $\%, \lambda$ wt. $x \%$ is thermal conductivity of epoxy sample with $\mathrm{X}$ wt.\% of the 
filling material in $\mathrm{W} \cdot \mathrm{m}^{-1} \cdot \mathrm{K}^{-1}$ and $\lambda$ w. $0 \%$ is thermal conductivity of pure epoxy sample also in $\mathrm{W} \cdot \mathrm{m}^{-1} \cdot \mathrm{K}^{-1}$.

TABLE 2 - Comparison of different experiments with AlN filler

\begin{tabular}{|r|r|r|r|r|}
\hline \multirow{2}{*}{ AlN } & \multicolumn{2}{|c|}{$[5]$} & \multicolumn{2}{c|}{$[12]$} \\
\cline { 2 - 5 } & \multicolumn{1}{|c|}{$\lambda$} & \multicolumn{1}{c|}{ p. c. } & \multicolumn{1}{c|}{$\lambda$} & \multicolumn{1}{c|}{ p. c. } \\
\hline wt.\% & $\mathrm{W} \cdot \mathrm{m}^{-1} \cdot \mathrm{K}^{-1}$ & $\%$ & $\mathrm{~W} \cdot \mathrm{m}^{-1} \cdot \mathrm{K}^{-1}$ & 0 \\
\hline 0 & 0,168 & 0 & 0,169 & 5,6 \\
\hline 2 & 0,1768 & 4,6 & 0,1785 & 11,2 \\
\hline 5 & 0,1851 & 10,2 & 0,188 & $\%$ \\
\hline
\end{tabular}

First sight on percentage change in TABLE 2 reports, that samples prepared in study [13] were slightly better in thermal conductivity.

\section{B. Boron Nitrid - BN}

On the other hand, many authors work with $\mathrm{BN}$ as a filling material. Summary of the experiments is presented in Fig. 5 and TABLE 3, where are also presented thermal conductivities of pure epoxies.

Samples produced in [5] were modified with $\gamma$ Glycidoxypropyltrimethoxysilane. The particle size range was between 4 and $40 \mathrm{~nm}$ with mostly amorphous crystalline form. Epoxy composites were produced from bisphenol-A epoxy resin (CY231) and hardener (HY925).

Following samples produced in [7] were also modified with silane coupling agent 3-(2,3-Epoxypropoxy) propyltrimethoxysilane. The samples were produced with speed mixer technique. Their APS is for hBN $70 \mathrm{~nm}$ and for cBN $150 \mathrm{~nm}$. Composites were produced from epoxy resin bisphenol-A diglycidyl ether CY225 and anhydrite hardener.

Ensuing samples produced in [19] were modified with 3\% wt. of 3-(2,3-Epoxypropoxy) propyltrime- thoxysilane. Authors compared speed mixer and solvent technique. The size distribution of the hBN particles was from 30 to $300 \mathrm{~nm}$. Composites were made from bisphenol-A diglycidyl ether (CY22S) and anhydrite hardener HY22S.

In subsequent article [30] the composites were prepared as a mixture of micro and nano particles in weight ratio 4:1 respectively. The particles diameter was $10 \mu \mathrm{m}$ and $50 \mathrm{~nm}$. Authors did not state the crystalline form of BN. Epoxy matrix was created from bisphenol A -aralhydrite HY-511 epoxy and hardener HY-651. No coupling agent was used according to the preparation process, which represented simplified solvent technique.

Authors in last investigated experiment [31] produced composite samples with filler grain diameter size $300 \mathrm{~nm}$ of unspecified BN crystalline form. No coupling agent was used. The base epoxy matrix was created from the same resins as [30].

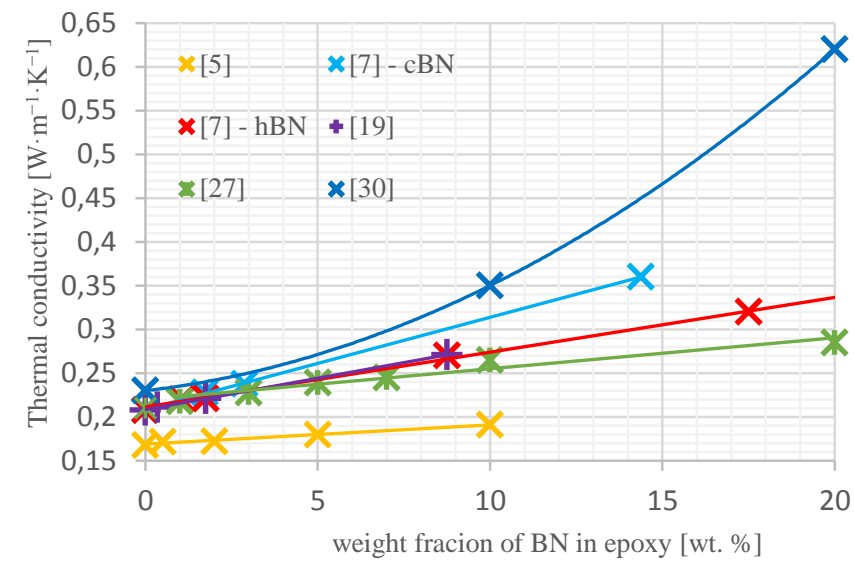

Fig. 5 - Epoxy composites with AlN nanoparticles, data were taken from [5], [7], [19], [27], [30]

The best results in improvement of the thermal conductivity posed micro-nano-composite [30] with the greatest gain size. The mixture of particles $10 \mu \mathrm{m}$ and $50 \mathrm{~nm}$ appears to be the most important factor in all investigated experiments. The thermal conductivity could be even higher if the authors would use coupling agent.

In nano scale, the size of particles in experiments [7] $\mathrm{hBN}$, [19] and [27] posed smaller difference, if we assume the influence of coupling agent in experiments [7] and [19].

On the other hand crystalline form of $\mathrm{cBN}$ significantly improves the thermal conductivity of resulting composite [7], where $\mathrm{cBN}$ posed significantly better results over $\mathrm{hBN}$. The particle size could pose there also a role. Completely undesirable for enrichment appears to be aBN [5].

TABLE 3 - Comparison of different experiments with BN filler

\begin{tabular}{|c|c|c|c|c|c|c|c|c|c|c|c|c|}
\hline \multirow{3}{*}{ BN } & \multicolumn{2}{|l|}{ [19] } & \multicolumn{2}{|l|}{$[5]$} & \multicolumn{2}{|l|}{ [7] } & \multicolumn{2}{|l|}{ [7] } & \multicolumn{2}{|l|}{$[30]$} & \multicolumn{2}{|l|}{ [27] } \\
\hline & \multicolumn{2}{|c|}{ hBN 30-300nm } & \multicolumn{2}{|c|}{$\mathrm{aBN} 4-40 \mathrm{~nm}$} & \multicolumn{2}{|c|}{$\mathrm{cBN} 150 \mathrm{~nm}$ APS } & \multicolumn{2}{|c|}{ hBN 70nm APS } & \multicolumn{2}{|l|}{$\mathrm{BN} * *$} & \multicolumn{2}{|c|}{$\mathrm{BN} 300 \mathrm{~nm}$} \\
\hline & $\lambda$ & p.c. & $\lambda$ & p.c. & $\lambda$ & p.c. & $\lambda$ & p.c. & $\lambda$ & p.c. & $\lambda$ & p.c. \\
\hline wt. $\%$ & $\mathrm{~W} \cdot \mathrm{m}^{-1} \cdot \mathrm{K}^{-1}$ & $\%$ & $\mathrm{~W} \cdot \mathrm{m}^{-1} \cdot \mathrm{K}^{-1}$ & $\%$ & $\mathrm{~W} \cdot \mathrm{m}^{-1} \cdot \mathrm{K}^{-1}$ & $\%$ & $\mathrm{~W} \cdot \mathrm{m}^{-1} \cdot \mathrm{K}^{-1}$ & $\%$ & $\mathrm{~W} \cdot \mathrm{m}^{-1} \cdot \mathrm{K}^{-1}$ & $\%$ & $\mathrm{~W} \cdot \mathrm{m}^{-1} \cdot \mathrm{K}^{-1}$ & $\%$ \\
\hline 0 & 0,208 & 0 & 0,168 & 0 & 0,208 & 0 & 0,208 & 0 & 0,23 & 0 & 0,21 & 0 \\
\hline 2 & $* 0,223$ & 7,1 & $* 0,173$ & 3,2 & $* 0,23$ & 10,3 & $* 0,224$ & 7,6 & $* 0,242$ & 5,3 & $* 0,227$ & 7,9 \\
\hline 10 & $* 0,28$ & 34,8 & 0,191 & 13,7 & $* 0,314$ & 50,7 & $* 0,274$ & 31,9 & $* 0,355$ & 54,3 & 0,265 & 26,2 \\
\hline
\end{tabular}

\section{THERMAL STRESS AND RELIABILITY}

The thermal stress that goes in hand with thermal expansion of insulation is very often a cause of insulation deterioration and failure. The thermal insulation classes [32] define the maximum operating temperature for each material or insulation system. These days in industry are commonly used classes $\mathrm{F}$ and $\mathrm{H}$ that can be designed for maximum temperature in winding $155^{\circ} \mathrm{C}$ and $180^{\circ} \mathrm{C}$ respectively.

The operating temperature of winding itself causes thermal stress to the insulation same as overheating during overloads. The high temperature causes oxidation of the insulation and 
oxidized insulation losses its dielectric and mechanical properties. The higher temperature of insulation is, the shorter is expected lifetime of the insulation as we can see in Fig. 6.

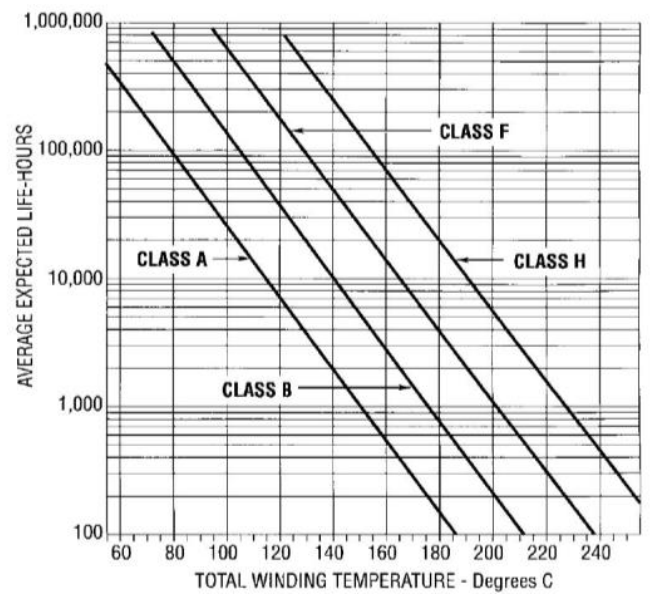

Fig. 6 - Temperature vs. life curves [33]

If we use an epoxy composite with higher thermal conductivity, the temperature in winding will decrease. Due to temperature decrease in winding we can expect improvement of insulation lifetime and operating reliability [34], [35]. For each $10^{\circ} \mathrm{C}$ decrease in temperature of winding will approximately double the average expected lifetime of the insulation - according to Fig. 6 .

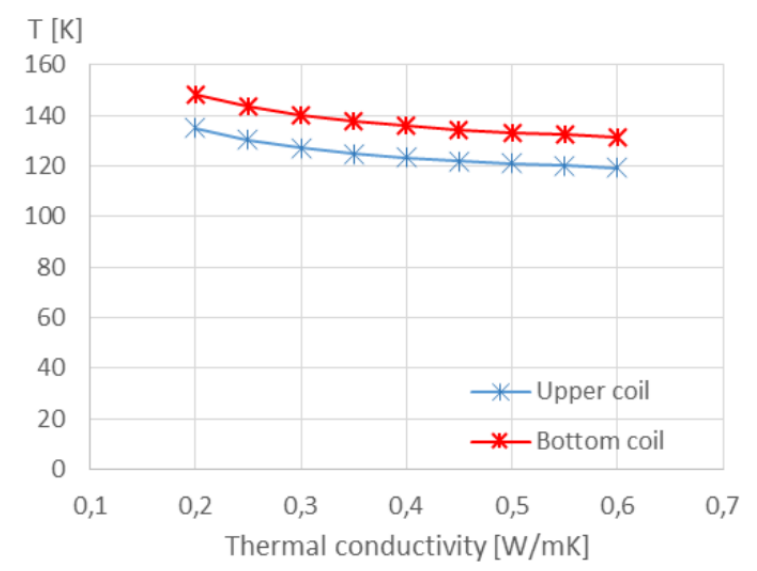

Fig. 7 - Predictive development of temperature in two layered form wound winding of a simulated machine [36]

In study [36] authors investigated development of temperature in a coil of winding according to the thermal conductivity of impregnating resin. The function of thermal conductivity of epoxy on the winding temperature is nonlinear as Fig. 7 presents. The most important thermal conductivity increase of epoxy is from 0,2 to $0,3 \mathrm{~W} \cdot \mathrm{m}^{-1} \cdot \mathrm{K}^{-1}$, where a coil of double layer winding reduced temperature for $9 \mathrm{~K}$. Further improvement of thermal conductivity from 0,3 to 0,55 $\mathrm{W} \cdot \mathrm{m}^{-1} \cdot \mathrm{K}^{-1}$ led to next decrease of temperature for $7 \mathrm{~K}$.

\section{DISCUSSION}

According to the Fig. 4 and Fig. 5 the thermal conductivity of epoxy resin can be slightly improved with low filling. With higher enrichment of particles the thermal conductivity increases. Due to this, we can expect reduction of temperature in windings of electric machines as presented in Fig. 7. The temperature reduction in winding will improve expected lifetime of insulation - Fig. 6 .

So the lifetime of insulation in operation of rotating machines can be rapidly improved due to addition of nano- or mircoparticles to the impregnating rein. Also the dielectric strength can be improved by addition of a nitrid filler [26].

Before wide application of these composites, first of all there should be conducted a survey exploring environmental sustainability and the influence of nanoparticles on ecosystems and living organisms. It should be investigated, that the used size of particles does not harm, choke up or blocks any internal organs of plants, animals or human bodies. Also recycle of the composite should be solved before wide application. Due to this investigation, we can avoid wellknown "DDT environmental impact" effect on the nature from the past.

From the physical point of view the comparison of different composites is almost impossible due to different weight of nitride particles. Because each crystalline form itself has different density e.g. hBN weights $2,1 \mathrm{~g} \cdot \mathrm{cm}^{-3}$ and $\mathrm{cBN}$ weights $3,45 \mathrm{~g} \cdot \mathrm{cm}^{-3}$. The resulting epoxy composite consisting of only $\mathrm{hBN}$ or $\mathrm{cBN}$ with the same weight fraction of the particles carries different volume fraction of them. Authors usually state only weight fraction, not the volume fraction. If the volume fraction would be stated in each article, than the results can be compared precisely.

AlN particles oxidation resistance should be investigated during the thermal aging of insulation so the properties of the composites can be verified as stable during the whole operation time of a machine.

Better thermal conductivity in the composites could be reached in selected direction with creation of thermally conductive pathways. Creation of thermally conductive pathways from a nitride particles can be further step in improvement of thermal conductivity and heat dissipation of electric machines. This procedure should be closely investigated due to non-uniform dispersion of particles and possible influence on dielectric breakdown strength of resulting composite.

\section{CONCLUSION}

Nitride particles possess good results in improvement of thermal conductivity of epoxy composites. The particle size, usage of coupling agent, amount of coupling agent and particle dispersion are very important factors in resulting thermal conductivity of epoxy composite. Improved thermal conductivity will positively influence the lifetime of insulation due to reduction of the temperature in windings.

Before wide application of these epoxide composites, the environmental safety and toxicity of particles should be closely investigated and verified. 


\section{REFERENCES}

[1] X. Huang, P. Jiang, and T. Tanaka, "A review of dielectric polymer composites with high thermal conductivity," IEEE Electr. Insul. Mag., vol. 27, no. 4, pp. 8-16, 2011.

[2] T. Tomášková and P. Trnka, "The influence of thermal properties of aluminum oxide on electrical insulating materials," 2014.

[3] J. K. Nelson, "Overview of nanodielectrics: Insulating materials of the future," 2007 Electr. Insul. Conf. Electr. Manuf. Expo, EEIC 2007, no. June, pp. 229-235, 2007.

[4] T. Tomášková, A. Čejková, and L. Harvánek, "Vliv tepelných vlastností materiálu na elektroizolační systémy," Electroscope, vol. $2,2016$.

[5] R. Kochetov, T. Andritsch, U. Lafont, P. H. F. Morshuis, S. J. Picken, and J. J. Smit, "Thermal behaviour of epoxy resin filled with high thermal conductivity nanopowders," 2009 IEEE Electr. Insul. Conf. EIC 2009, no. June, pp. 524-528, 2009.

[6] Y. Xu, D. D. L. Chung, and C. Mroz, "Thermally conducting aluminum nitride polymer-matrix composites," Compos. - Part A Appl. Sci. Manuf., vol. 32, no. 12, pp. 1749-1757, 2001.

[7] I. A. Tsekmes et al., "How different fillers affect the thermal conductivity of epoxy composites," in 2014 IEEE Conference on Electrical Insulation and Dielectric Phenomena (CEIDP), 2014, pp. 647-650.

[8] P. Beiss, R. Ruthardt, and H. Warlimont, Eds., Powder Metallurgy Data. Refractory, Hard and Intermetallic Materials, vol. $2 \mathrm{~A} 2$. Berlin/Heidelberg: Springer-Verlag, 2002.

[9] P. Beiss, R. Ruthardt, and H. Warlimont, Eds., Powder Metallurgy Data. Refractory, Hard and Intermetallic Materials, vol. 2A2. Berlin/Heidelberg: Springer-Verlag, 2002.

[10] Z. Wang, T. Iizuka, M. Kozako, Y. Ohki, and T. Tanaka, "Development of epoxy/BN composites with high thermal conductivity and sufficient dielectric breakdown strength part IIbreakdown strength," IEEE Trans. Dielectr. Electr. Insul., vol. 18, no. 6, pp. 1973-1983, 2011.

[11] T. Tanaka, "Dielectric nanocomposites with insulating properties," IEEE Trans. Dielectr. Electr. Insul., vol. 12, no. 5, pp. 914-928, Oct. 2005.

[12] Y. Xu and D. D. L. Chung, "Increasing the thermal conductivity of boron nitride and aluminum nitride particle epoxy-matrix composites by particle surface treatments," Compos. Interfaces, vol. 7, no. 4, pp. 243-256, Jan. 2000

[13] R. Kochetov, T. Andritsch, U. Lafont, P. H. F. Morshuis, and J. J. Smit, "Thermal conductivity of nano-filled epoxy systems," Annu. Rep. - Conf. Electr. Insul. Dielectr. Phenomena, CEIDP, pp. 658 661, 2009.

[14] T. Iizuka, Y. Ohki, and T. Tanaka, "Effects of coupling agent and filler dispersion on V-t characteristics of epoxy/silica nanocomposites," Proc. Int. Symp. Electr. Insul. Mater., pp. 60-63, 2008.

[15] T. Andritsch, R. Kochetov, P. H. F. Morshuis, and J. J. Smit, "Short term DC breakdown and complex permittivity of $\mathrm{Al} 2 \mathrm{O} 3-$ and $\mathrm{MgO}-$ epoxy nanocomposites," Electr. Insul. Dielectr. Phenom. (CEIDP), 2010 Аппи. Rep. Conf., pp. 1-4, 2010.

[16] R. Kochetov, T. Andritsch, U. Lafont, P. H. F. Morshuis, S. J. Picken, and J. J. Smit, "Preparation and dielectric properties of epoxy - BN and epoxy - AIN nanocomposites," 2009 IEEE Electr. Insul. Conf. EIC 2009, no. June, pp. 397-400, 2009.

[17] R. Kochetov, T. Andritsch, U. Lafont, P. H. F. Morshuis, and J. J. Smit, "Effects of inorganic nanofillers and combinations of them on the complex permittivity of epoxy-based composites," Conf. Rec. IEEE Int. Symp. Electr. Insul., pp. 1-5, 2010.

[18] C. Nyamupangedengu and D. R. Cornish, "Time-evolution phenomena of electrical tree partial discharges in Magnesia, Silica and Alumina epoxy nanocomposites," IEEE Trans. Dielectr. Electr. Insul., vol. 23, no. 1, pp. 85-94, Feb. 2016.

[19] I. A. Tsekmes, R. Kochetov, P. H. F. Morshuis, and J. J. Smit, "Measuring and modeling the thermal conductivity of epoxy Boron nitride nanocomposites," in Proceedings of 2014 International Symposium on Electrical Insulating Materials, 2014, pp. 26-29.

[20] W. Wang, W. Bian, and Y. Yang, "Incorporation of Nanodiamond into an Epoxy Polymer Network with High Thermal Conductivity for Electrical Insulations," pp. 1-4, 2016.

[21] I. A. Tsekmes, P. H. F. Morshuis, J. J. Smit, and R. Kochetov, "Enhancing the Thermal and Electrical with the Addition of Nanofillers," Electr. Insul. Mag. IEEE, vol. 31, no. 3, pp. 32-42, 2015.

[22] L. Harvánek, J. Hornak, V. Mentlík, P. Trnka, T. Džugan, and A. Components, "Influence of Nano and Microparticles on the Development of Electrical Trees," pp. 1-4, 2016.

[23] R. Kochetov and J. J. Smit, "Thermal and Electrical Behaviour of Epoxy-based Microcomposites Filled with $\mathrm{Al} 2 \mathrm{O} 3$ and $\mathrm{SiO} 2$ Particles," vol. 7, pp. 909-911, 2010.

[24] I. A. Tsekmes, R. Kochetov, P. H. F. Morshuis, and J. J. Smit, "The role of particle distribution in the dielectric response of epoxy???boron nitride nanocomposites," J. Mater. Sci., vol. 50, no. 3, pp. 1175-1186, 2015.

[25] L. Harvánek, T. Tomášková, M. Svoboda, and V. Mentlík, "Composites with Nanosilica," 2015.

[26] M. Donnay, S. Tzavalas, and E. Logakis, "Boron nitride filled epoxy with improved thermal conductivity and dielectric breakdown strength," Compos. Sci. Technol., vol. 110, pp. 152-158, 2015.

[27] B. X. Du and M. Xiao, "Thermal accumulation and tracking failure process of BN-filler epoxy-matrix composite," IEEE Trans. Dielectr. Electr. Insul., vol. 20, no. 6, pp. 2270-2276, Dec. 2013.

[28] J. Katayama, Y. Ohki, N. Fuse, M. Kozako, and T. Tanaka, "Effects of nanofiller materials on the dielectric properties of epoxy nanocomposites," IEEE Trans. Dielectr. Electr. Insul., vol. 20, no. 1 , pp. $157-165,2013$

[29] I. A. Tsekmes, R. Kochetov, P. H. F. Morshuis, and J. J. Smit, "Impact of particle distribution on the electrical conductivity of epoxy nanocomposites," in 2015 IEEE Electrical Insulation Conference (EIC), 2015, pp. 337-340

[30] M. Xiao and B. X. Du, "Effects of high thermal conductivity on temperature rise of epoxy cast winding for power transformer," IEEE Trans. Dielectr. Electr. Insul., vol. 23, no. 4, pp. 2413-2420, Aug. 2016.

[31] B. X. Du and M. Xiao, "Thermal accumulation and tracking failure process of BN-filler epoxy-matrix composite," IEEE Trans. Dielectr. Electr. Insul., vol. 20, no. 6, pp. 2270-2276, Dec. 2013.

[32] G. Stone, I. Culbert, E. Boulter, and H. Dhirani, Electrical Insulation for Rotating Machines, no. 2. 2014.

[33] A. H. Bonnett, "A comparison between insulation systems available for PWM inverter fed motors," Proc. 1996 IAS Pet. Chem. Ind Tech. Conf., vol. 33, no. 5, pp. 49-60, 1996.

[34] J. Pyrhonen, T. Jokinen, and V. Hrabovcová, Design of Rotating Electrical Machines. 2014.

[35] B. X. Du, M. Xiao, X. L. Li, and Y. Liu, "Effect of thermal conductivity on tracking failure of epoxy/BN composite under pulse strength," Proc. IEEE Int. Conf. Solid Dielectr. ICSD, no. Ciced, pp. 607-610, 2013

[36] T. Tomaskova, R. Pechanek, and V. Kindl, "Benefits of upgrading insulating materials to operating temperature of induction motor," 2015 17th Eur. Conf. Power Electron. Appl. EPE-ECCE Eur. 2015, 2015 . 